
\title{
$\begin{array}{ll}\text { Research Square } & \begin{array}{l}\text { Preprints are preliminary reports that have not undergone peer review. } \\ \text { They should not be considered conclusive, used to inform clinical practice, } \\ \text { or referenced by the media as validated information. }\end{array}\end{array}$
}

\section{Alien Advantage in Endozoochorous Seed Dispersal of Aquatic Plants}

\section{Ádám Lovas-Kiss}

Centre for Ecological Research: Okologiai Kutatokozpont

Maria José Navarro

Donana Biological Station: Estacion Biologica de Donana CSIC

Orsolya Vincze ( $\square$ vincze.orsolya@ecolres.hu)

Centre for Ecological Research: Okologiai Kutatokozpont https://orcid.org/0000-0001-5789-2124

Viktor Löki

Centre for Ecological Research: Okologiai Kutatokozpont

Renáta Urgyán

Centre for Ecological Research: Okologiai Kutatokozpont

Falicia Kapusi Pallér

Centre for Ecological Research: Okologiai Kutatokozpont

\section{Casper van Leeuwen}

Netherlands Institute of Ecology: Nederlands Instituut voor Ecologie

Andy J. Green

Donana Biological Station: Estacion Biologica de Donana CSIC

Balázs András Lukács

Centre for Ecological Research: Okologiai Kutatokozpont

\section{Research Article}

Keywords: Anas platyrhynchos, endozoochory, plant-animal interactions, seed dispersal, seed traits, seed volume

Posted Date: March 7th, 2022

DOI: https://doi.org/10.21203/rs.3.rs-1343712/v1

License: (c) (1) This work is licensed under a Creative Commons Attribution 4.0 International License. Read Full License 


\section{Abstract}

The expansion of alien plant species is of global concern, yet our understanding of their dispersal mechanisms is limited, especially regarding the role of migratory birds. We hypothesize that invasiveness of alien wetland plants might depend on specific adaptations that ensure high seed survival in the digestive tract of waterfowl, ensuring their efficient spread across sites. In a controlled feeding experiment, we compared the endozoochorous dispersal ability of twelve congeneric alien and native wetland plant species, with a particular focus on seed passage rate, gut retention time, germinability, and time to germination. Germination dynamics were also compared to those of control seeds. Finally, we test how seed traits explain the observed differences. Gut passage rate was higher and time to germination faster, but retention time and germinability were lower in alien than in native species. Controlling for seed traits did not alter these conclusions. Among control seeds, aliens germinated faster and their germinability was higher than in natives. Seed traits explained differences in germinability but not time to germination in control seeds. Our results indicate that endozoochory provides competitive advantage to alien plants by ensuring higher propagule pressure in new environments, potentially ensuring their quick spread.

\section{Introduction}

Plant invasions have strong effects on ecosystems, ecosystem services and they contribute to the current biodiversity crisis. Alien plant species first have to overcome geographic, environmental, reproductive and dispersal barriers to establish in areas outside their former distribution ranges (Richardson et al. 2000; Blackburn et al. 2011). A major scientific challenge on biological invasions is to understand which factors determine the further spread of human-introduced alien species after their naturalization, and previous work has sought to identify possible traits or trait syndromes associated with the competitive success of alien species (Crawley et al., 1996; Pyšek \& Richardson, 2008). Previous studies targeting to explain the dispersibility of native and alien species compare the variance of traits (seed mass, seed size or spread rate) that basically have multiple ecological functions (van Kleunen et al. 2015). Moreover, they ignore the long-distance dispersal events and their associated effects on the performance of these traits in each function (Nathan et al. 2008).

Range expansion of alien species can occur slowly and steadily via local dispersal mechanisms (e.g. wind, water), but can also occur by long-distancedispersal (LDD) events such as zoochory (Higgins and Richardson 1999; Nathan et al. 2008). Invasive alien plants may be expected to have a better dispersal capacity than native plants, but accurate comparisons among native and alien species depends on solid knowledge on all dispersal mechanisms used by plants in the field, at different spatial scales. Endozoochory (transport of diaspores by animals via gut passage) is particularly important for LDD (Bullock et al. 2017), yet has been understudied for plants lacking a fleshy fruit (Green et al. 2021). Fishes, mammals and birds are all important vectors, but migratory birds are particularly important for LDD (Viana et al. 2016).

Historical and contemporary evidence demonstrates that migratory waterbirds can play a key role in the spread of alien plant species (Green, 2016). However, their role in LDD of alien plants via endozoochory has often been overlooked because of the shortcomings of the dispersal syndrome paradigm (Green et al. 2021), and because the research field of invasion biology focuses more on the consequences of human activities than on natural dispersal mechanisms. Therefore, there are major knowledge gaps in our understanding of alien species LDD, and our knowledge is biased towards endozoochory by frugivorous vertebrates (van Leeuwen, 2018). Less attention has been paid to alien plants without fleshy fruits and non-frugivorous vertebrates (i.e. non-classical endozoochory, see Green et al., 2019, 2021).

Wetlands can hold a great number of alien species, including many of the most invasive plant species (Zedler and Kercher 2004). A diversity of waterbirds act as plant vectors, including gulls (Lovas-Kiss et al., 2018; Martín-Vélez et al., 2021), cormorants (van Leeuwen, Lovas-Kiss, Ovegård, \& Green, 2017), herons (Navarro-Ramos et al. 2021), geese (Hattermann et al. 2019), shorebirds (Lovas-Kiss et al. 2019), and especially dabbling ducks (Soons, Brochet, Kleyheeg, \& Green, 2016; van Leeuwen, van der Velde, van Groenendael, \& Klaassen, 2012). These studies show that waterbirds can help the spread of a wide range of alien species, but there is a lack of experimental studies comparing the effect of endozoochory on the survival and germination of alien and native plants. Passage through the avian gut has diverse effects on the physical and physiological attributes of seeds, and seed survival is influenced by traits such as shape, size, thickness of the seed coat and seed hardness (Traveset et al., 2007; Costea et al., 2019; Lovas-Kiss et al., 2020). These traits also influence retention time, which in turn can determine dispersal distance (Martín-Vélez et al. 2021). Experimental approaches are indispensable if we aim to investigate the role of endozoochory in plant invasions, to identify traits that determine their success, and so be able to predict invasiveness of different taxa (Gioria and Pyšek 2017).

In one study making a direct experimental comparison of the waterbird-mediated endozoochorous dispersal ability of alien and native plant species (GarcíaÁlvarez et al. 2015), mallards (Anas platyrhynchos) and greylag geese (Anser anser) were fed with seeds of two native and two alien plant species. No consistent differences were found between alien and native species, e.g. the alien water primrose (Ludwigia grandiflora) had the highest survival rate during gut passage, and the alien cordgrass (Spartina densiflora) the lowest. This illustrates the need to incorporate seed traits into future research, to better explain the species-specific effects of endozoochory on seed survival, retention times and germination capacity.

In this study, we compare the potential for endozoochory between closely related alien and native wetland plant species by waterbirds. Our aim was to investigate whether alien and native species differed consistently across six genera in their potential for waterbird-mediated dispersal, using an experimental approach. Because alien species may outperform their native competitors during distinct phases of invasions, we hypothesized (1) that during and after gut passage by waterbirds alien species would have higher seed survival, longer gut retention times, higher germinability and a reduced time to germination; and (2) that seed traits would partly explain these patterns, because seed traits such as a smaller size or rounder shape can promote seed survival, whereas a larger size can increase retention times (Lovas-Kiss et al. 2020). Traits of alien and native plant species generally overlap, hence, we measured and incorporated seed traits into the analyses to investigate their overall effects.

\section{Materials And Methods}


Plant species and seed traits

To investigate the dispersal differences between alien and native congeneric species, we conducted a controlled feeding experiment. In total, twelve wetland plant taxa, six native and six alien species (which can also be considered invasive) were used for the experiments (Fig. 1). The following alien species were included: Juncus tenuis, Lindernia dubia, Typha laxmanii, Najas gracillima, Bidens frondosa, Cyperus difformis. All these species are also treated as invasive throughout their introduced ranges. (The details of species invasion character can be found in Online Resource 1). We paired these with native European congeners: Juncus compressus, Lindernia procumbens, Typha angustifolia, Najas minor, Bidens tripartita, Cyperus fuscus. These species cover six plant families. All the seeds were collected in Hungarian wetlands during the summer before the experiments. The seeds were stored in the dark at $4^{\circ} \mathrm{C}$ for several months until the experiments began. All these species are considered to have physiological dormancy (Baskin and Baskin 2014).

We measured two key seed traits for each species: seed volume and seed shape (Table 1; Lovas-Kiss et al., 2020). For each species, the width, height and length of 10 seeds were measured using the TCapture (version 5.1.) software on a microscope. Seed shape were calculated according to Bekker et al. (1998). Seed volume calculated as width $\times$ height $\times$ length.

Table 1

Average seed traits of plant species included in the experiment. Seed shape index can vary from 0 (perfect sphere) to 0.2 (slim disk or a thin needle).

\begin{tabular}{|c|c|c|c|}
\hline & & Volume $\left(\mathrm{mm}^{3}\right.$; mean \pm S.E. $)$ & Shape (mean \pm S.E.) \\
\hline Cyperus fuscus & native & $0.084 \pm 0.006$ & $0.085 \pm 0.004$ \\
\hline Cyperus difformis & alien & $0.046 \pm 0.001$ & $0.045 \pm 0.002$ \\
\hline Bidens tripartita & native & $6.297 \pm 0.586$ & $0.135 \pm 0.005$ \\
\hline Bidens frondosa & alien & $8.312 \pm 0.539$ & $0.109 \pm 0.004$ \\
\hline Lindernia procumbens & native & $0.006 \pm 0.000$ & $0.063 \pm 0.005$ \\
\hline Lindernia dubia & alien & $0.009 \pm 0.000$ & $0.049 \pm 0.004$ \\
\hline Najas minor & native & $0.351 \pm 0.014$ & $0.133 \pm 0.000$ \\
\hline Najas gracillima & alien & $0.516 \pm 0.023$ & $0.134 \pm 0.001$ \\
\hline Juncus compressus & native & $0.024 \pm 0.001$ & $0.046 \pm 0.003$ \\
\hline Juncus tenuis & alien & $0.023 \pm 0.001$ & $0.036 \pm 0.002$ \\
\hline Typha angustifolia & native & $0.034 \pm 0.001$ & $0.103 \pm 0.003$ \\
\hline Typha laxmanii & alien & $0.063 \pm 0.002$ & $0.128 \pm 0.003$ \\
\hline
\end{tabular}

Experimental set-up

In the feeding experiment, we used eight mallards (Anas plathyrhynchos). The birds were obtained from a captive population maintained by a local breeder, and had been fed freshly handpicked plants and mixed grains during their lifetime. All birds were born and raised in captivity and were adults (1.5 years) at the time of the experiment. Mean body mass was $1.05 \mathrm{~kg} \pm 0.19$ S.D. Prior to the experiments, the mallards were housed communally in outdoor facilities and were fed with mixed grains (corn, wheat, oat) and green leaves (e.g. Stellaria media, Taraxacum officinale). Grit was freely available to the birds outside the experimental trials. The experiment had ethical approval from the scientific council (serial number will be provided following the double blind peer review process).

The experimental procedure was as follows. Each mallard was force-fed with a congeneric pair of alien and native plant species, using a plastic cone to ensure that all seeds passed to the oesophagus. This method excludes seed handling by the birds, but waterfowl have soft bills that do not damage seeds (Gurd 2007). We conducted three feeding trials on the 1st, 3rd and 5th of April 2019. In each trial, 500 seeds were fed per plant species, with two plant species at the same time (1000 seeds) per individual mallard. To minimize effects of individual differences among mallards (Pollux 2017), we randomized which plant species pair was fed to which mallard in the consecutive trials. $48 \mathrm{~h}$ before the force-feeding, the mallards were moved individually to cages with mesh floors $(60 \times 40 \times 50 \mathrm{~cm})$ equipped with bowls filled with water and with mixed and minced grains (corn, wheat, oat) for the animals to feed and drink ad libitum.

Plastic sheets and trays were placed under the cages to allow controlled faecal sample collection. Droppings were collected from the trays at $1,2,4,6,8,12$, and $24 \mathrm{~h}$ after seed ingestion. Faecal samples were collected in plastic bags and placed in the fridge at $4 \mathrm{C}^{\circ}$ until the separation of the seeds within $1-46$ days. Faecal samples were washed through a $100 \mu \mathrm{m}$ sieve using deionized water. Seeds were then separated under a stereomicroscope. Due to its potntial effect on seed viability, separation time (i.e. number of days passed between sample collection and processing) was recorded (Barnea et al. 1991). Intact seeds were immediately placed to germinate in Petri-dishes filled with moistened filter paper. For each plant species, 100 undigested seeds were also placed in Petridishes under the same germination conditions as controls. Petr dishes were kept at room temperature $\left(20^{\circ} \mathrm{C}\right)$ under $14 \mathrm{~h}$ light $/ 8 \mathrm{~h}$ dark cycles, illuminated with Sylvania GRO-LUX F18W/GRO-T8 lamps. Each Petri-dish was monitored daily for two months, and germinated seeds were removed.

Statistical analyses 
To test how seed passage (i.e. proportion of egested seeds) differed between alien and native species, we constructed two generalized linear mixed models (GLMM) with binomial error distributions. First, we constructed a base model, in which seed passage ( 1 if it passed the digestive tract, 0 if it did not) was used as dependent variable, while origin (alien/native) was used as a fixed explanatory variable. Species pair (congeneric native and alien pair), experiment ID (i.e. feeding trial identifier) and duck ID (individual duck identifier) were included as categorical random intercepts. Second, in order to test how seed traits explain differences in passage rates between alien and native species, we added seed traits as predictor variables to the above base model. To test for differences in germinability between alien and native species, we constructed similar GLMMs, retaining model type and structure, but using germinability as a dependent variable (1 if germinated, 0 if not). Models of germinability also included separation time as a covariate.

To investigate how retention time and time to germination differs between alien and native species, we constructed linear mixed models ((G)LMMs) with Poisson and Gaussian error distributions respectively. First, we built base models using retention time (i.e., hours passed between seed ingestion and egestion) and time to germination (i.e., number of days until germination, log-transformed) as a dependent variables. Both models included origin as a fixed factor (and separation time as a covariate in case of time to germination due to its potentially negatively effect on seed viability (Guttal et al., 2011)). Species pair, experimental ID and duck ID were used as random factors in both models. Second, to test how differences in retention time or time to germination between alien and native plants is explained by seed traits, we added the traits as predictor variables to the above base models.

Models exploring germinability and time to germination were run also for control seeds using identical model structures as for passed seeds, but not including separation time. To test for potential differences in germinability and germination time between native and alien species, we constructed additional GLMMs without covariates, using species pair as a random factor.

In all models, seed traits were log-transformed. Statistical significance of fixed terms in gaussian LMMs was accepted if $|\mathrm{t}|>2.00$ (Crawley, 2007$)$. All statistical analysis and graphical presentations were performed using R statistical and programming environment, version 4.0.4 (R Core Team, 2021). All LMMs were run using R package Ime4 and functions Imer (for models with Gaussian error disteributions) or g/mer (for models with binimola/Poisson error distributions) (Bates et al., 2015).

\section{Results}

Seed passage and retention times

Seed passage (i.e. the proportion of seeds recovered after gut passage) was significantly lower for native than for alien plant species (Table 2). For all species combined, $33 \%$ of the alien seeds passed the digestive tract of mallards, compared to $29 \%$ of native seeds, indicating a slightly higher probability of seeds of alien plant species to pass the digestive tract of mallards (Table 3). However, effects were genera-specific (Table 2). Models also including seed traits, indiacted that neither seed volume nor seed shape influenced seed passage. Consequently, the effect of seed origin remained significant after including seed traits in the model, indicating higher seed passage in alien compared to native plants (Table 3).

Table 2

Descriptive statistics of the experiment results on the number of passed seeds, number of seeds germinated and time to germination according to nat

\begin{tabular}{|c|c|c|c|c|c|c|c|c|c|c|c|}
\hline & Native & & & & & & & Alien & & & \\
\hline $\begin{array}{l}\text { Species } \\
\text { pair }\end{array}$ & $\begin{array}{l}\text { Seeds } \\
\text { fed }\end{array}$ & $\begin{array}{l}\text { Seeds } \\
\text { passed }\end{array}$ & $\begin{array}{l}\text { Passed } \\
\text { seeds } \\
\text { per } \\
\text { mallards } \\
\text { (mean } \pm \\
\text { S.E.) }\end{array}$ & $\begin{array}{l}\text { Proportion } \\
\text { of passed } \\
\text { germinated } \\
\text { seeds }\end{array}$ & $\begin{array}{l}\text { Proportion of } \\
\text { control germinated } \\
\text { seeds }\end{array}$ & $\begin{array}{l}\text { Time to } \\
\text { passed } \\
\text { seeds } \\
\text { germination } \\
\text { (mean days } \\
\pm \text { S.E. } \pm \text { C.V.) }\end{array}$ & $\begin{array}{l}\text { Time to } \\
\text { control } \\
\text { seeds } \\
\text { germination } \\
\text { (mean days } \\
\pm \text { S.E. } \pm \\
\text { C.V.) }\end{array}$ & $\begin{array}{l}\text { Seeds } \\
\text { fed }\end{array}$ & $\begin{array}{l}\text { Seeds } \\
\text { passed }\end{array}$ & $\begin{array}{l}\text { Passed } \\
\text { seeds } \\
\text { per } \\
\text { mallards } \\
\text { (mean } \pm \\
\text { S.E.) }\end{array}$ & $\begin{array}{l}\text { Proportion } \\
\text { of passed } \\
\text { germinatec } \\
\text { seeds }\end{array}$ \\
\hline Bidens & 1500 & 16 & $\begin{array}{l}0.001 \pm \\
0.0002\end{array}$ & 0.09 & 0.02 & $\begin{array}{l}9 \pm 2.449 \pm \\
0.608\end{array}$ & $\begin{array}{l}37.52 \pm \\
0.366 \pm \\
0.098\end{array}$ & 2500 & 19 & $\begin{array}{l}0.001 \pm \\
0.0008\end{array}$ & 0.029 \\
\hline Cyperus & 2000 & 838 & $\begin{array}{l}0.059 \pm \\
0.019\end{array}$ & 0.361 & 0.97 & $\begin{array}{l}4.815 \pm \\
0.1799 \pm \\
0.924\end{array}$ & $\begin{array}{l}11.59 \pm \\
0.531 \pm \\
0.458\end{array}$ & 2000 & 739 & $\begin{array}{l}0.045 \pm \\
0.004\end{array}$ & 0.38 \\
\hline Lindernia & 2000 & 590 & $\begin{array}{l}0.042 \pm \\
0.019\end{array}$ & 0.164 & 0.14 & $\begin{array}{l}7.969 \pm \\
0.552 \pm \\
1.107\end{array}$ & $\begin{array}{l}6.33 \pm \\
0.965 \pm \\
0.247\end{array}$ & 2000 & 604 & $\begin{array}{l}0.043 \pm \\
0.014\end{array}$ & 0.268 \\
\hline Najas & 2000 & 579 & $\begin{array}{l}0.041 \pm \\
0.014\end{array}$ & 0.268 & 0.1 & $\begin{array}{l}14.004 \pm \\
1.042 \pm \\
1.059\end{array}$ & $\begin{array}{l}34.32 \pm \\
0.848 \pm \\
0.247\end{array}$ & 2000 & 750 & $\begin{array}{l}0.053 \pm \\
0.014\end{array}$ & 0.055 \\
\hline Juncus & 2000 & 741 & $\begin{array}{l}0.053 \pm \\
0.007\end{array}$ & 0.222 & 1 & $\begin{array}{l}32.203 \pm \\
0.541 \pm \\
0.303\end{array}$ & $\begin{array}{l}23.44 \pm \\
0.446 \pm \\
0.190\end{array}$ & 2000 & 963 & $\begin{array}{l}0.069 \pm \\
0.016\end{array}$ & 0.157 \\
\hline Typha & 2000 & 736 & $\begin{array}{l}0.053 \pm \\
0.010\end{array}$ & 0.418 & 0.63 & $\begin{array}{l}8.731 \pm \\
0.455 \pm \\
1.189\end{array}$ & $\begin{array}{l}20.83 \pm \\
1.316 \pm \\
0.632\end{array}$ & 2000 & 922 & $\begin{array}{l}0.066 \pm \\
0.011\end{array}$ & 0.355 \\
\hline
\end{tabular}


Table 3

Result of models exploring variation in passage rate, retention time, germinability or germination time. Some cells provide two values: effect of the particular predictor in the base model (without seed traits) and in the multivariate model (including seed traits). Positive slopes of origin indicate higher values in the dependent variable of native species. Higher values of seed shape indicate more elongated shape; Higher seed volume indicate larger seeds. In case of models with gaussian error distribution (i.e. time to germination) $|t|>2.00$ indicates statistically significant effects. Significant effects are also marked in bold.

\begin{tabular}{|c|c|c|c|c|}
\hline & Estimates & S.E. & $\mathbf{Z}$ & $\operatorname{Pr}(>|z|)$ \\
\hline \multicolumn{5}{|c|}{ Passage rate in passed seeds } \\
\hline Intercept & $-1.172 /-0.352$ & 0.659 / 0.919 & $-1.776 /-0.383$ & $0.075 / 0.702$ \\
\hline Origin & $-0.202 /-0.320$ & $0.031 / 0.072$ & $-6.565 /-4.425$ & $<0.001 /<0.001$ \\
\hline Seed shape & 0.225 & 0.155 & 1.455 & 0.146 \\
\hline Seed volume & 0.103 & 0.111 & 0.934 & 0.350 \\
\hline \multicolumn{5}{|c|}{ Retention time in passed seeds } \\
\hline Intercept & $1.270 / 4.493$ & $0.146 / 1.147$ & $8.675 / 3.917$ & $<0.001 /<0.001$ \\
\hline Origin & $0.093 /-0.457$ & $0.012 / 0.028$ & $7.435 /-15.850$ & $<0.001 /<0.001$ \\
\hline Seed shape & -0.025 & 0.047 & -0.550 & 0.582 \\
\hline Seed volume & 1.367 & 0.060 & 22.566 & $<0.001$ \\
\hline \multicolumn{5}{|c|}{ Germinability of control seeds } \\
\hline Intercept & $0.371 / 6.016$ & $1.199 / 2.268$ & $0.309 / 2.652$ & $0.757 / 0.008$ \\
\hline Origin & $-0.681 / 0.082$ & $0.180 / 0.334$ & $3.787 / 0.248$ & $<0.001 / 0.804$ \\
\hline Seed shape & 4.170 & 0.821 & 5.077 & $<0.001$ \\
\hline Seed volume & -2.017 & 0.609 & -3.311 & $<0.001$ \\
\hline \multicolumn{5}{|c|}{ Germinability of passed seeds } \\
\hline Intercept & $-0.698 /-4.921$ & $0.535 / 1.040$ & $-1.302 /-4.730$ & $0.193 /<0.001$ \\
\hline Origin & $0.571 / 1.356$ & $0.059 / 0.137$ & $9.530 / 9.862$ & $<0.001 /<0.001$ \\
\hline Separation time & $-0.918 /-1.227$ & $0.081 / 0.098$ & $-11.335 /-12.527$ & $<0.001 /<0.001$ \\
\hline Seed shape & -1.081 & 0.324 & -3.332 & 0.0008 \\
\hline \multirow[t]{2}{*}{ Seed volume } & -0.568 & 0.209 & -2.712 & 0.006 \\
\hline & Estimates & S.E. & t-value & \\
\hline \multicolumn{5}{|c|}{ Time to germination in control seeds } \\
\hline Intercept & $3.094 / 0.708$ & $0.184 / 0.521$ & $16.754 / 1.358$ & \\
\hline Origin & $0.066 / 0.162$ & $0.030 / 0.071$ & 2.154 / 2.271 & \\
\hline Seed shape & -1.211 & 0.162 & -7.450 & \\
\hline Seed volume & 0.475 & 0.104 & 4.530 & \\
\hline \multicolumn{5}{|c|}{ Time to germination in passed seeds } \\
\hline Intercept & $2.397 / 0.252$ & $0.284 / 0.361$ & 8.419 / 0.699 & \\
\hline Origin & $-0.395 /-0.063$ & $0.025 / 0.045$ & $-15.687 /-1.376$ & \\
\hline Separation time & $-0.027 /-0.072$ & $0.031 / 0.028$ & $-0.899 /-2.564$ & \\
\hline Seed shape & -0.851 & 0.088 & -9.625 & \\
\hline Seed volume & 0.030 & 0.074 & 0.413 & \\
\hline
\end{tabular}

Models of retention time indicated significant differences between alien and native taxa, with the latter spending more time in the digestive tract of birds (Table 3). Nevertheless, when seed traits were introduced to this model the trend has changed, indicating that native seeds had shorter retention for their volume than aliens. The latter model also indicated that larger seeds had longer retention times (Table 3).

Seed germinability

Control seeds of native species had significantly lower germinability than seeds of alien plants (Table 2 and 3 ). In contrast, after gut passage, intact seeds of native plants had significantly higher germinability than seeds of alien plants. Longer separation time significantly reduced germinability (Table 3 ). After 
correcting for effects of seed traits, seed origin no longer explained differences in germinability of control seeds. For control seeds, germinability of smaller, elongated seeds was higher, whereas after gut passage germinability was higher for smaller, rounder seeds (Table 2 and 3 ). Hence gut passage disproportionately reduced the germinability of more elongated seeds.

After gut passage, germinability remained significantly higher for native species when traits were included in the model, and separation time retained a significant negative effect (Table 3).

Time to germination

Among controls, native seeds needed significantly more days to germinate compared to alien ones (Table 2 and 3 ). This trend remained consistent after including seed traits to the model. Seed shape had a significant negative effect on the time to germination, indicating that elongated seeds germinate faster. Moreover, seed volume also had a significant positive effect on the time to germination, indicating that smaller seeds germinate faster.

In case of passed seeds, alien species needed significantly more time to germinate than natives (Table 3). When seed traits were included in the model this difference was no longer significant, suggesting that the observed difference is explained by the alien-native differences in seed shape. As the delay between seed egestion and beginning of the germination test (i.e. separation time) increased, the time required for germination decreased. Seed shape had a similar influence as for control seeds, with elongated seeds germinating faster after gut passage. We found that four native species and three alien species germinated earlier after gut passage then in controls (Table 2). The confidence intervals of the dataset indicate that compared to control seeds, gut passage did not affect the plasticity of time to germination among native and alien species (Online Resource 2).

\section{Discussion}

This experimental study showed that waterbirds can play an important role in dispersal of both native and alien plant species. Seeds of all native and alien plant taxa were retained for up to 24 hours in the digestive system of birds, and germinated after gut passage. We also found strong effects of seed traits on all aspects of the endozoochory process. This suggests that invasive species may have particular traits that correlate with a higher endozoochory potential, and our experimental approach can be useful to identify traits that facilitate long-distance dispersal of alien species.

Effect of passage rate and retention time

Supporting our first hypothesis, we found that alien species have a higher overall passage rate than native species. This greater seed survival of alien species might be explained by the shorter retention time of alien plant seeds in the digestive tract of waterfowl. This result also indicated that, alien wetland plant species can have higher propagule pressure, which is a significant predictor of invasiveness (Colautti et al., 2006). A high propagule pressure increases the chances of establishing self-sustaining populations in new environments (Lockwood et al. 2009). Previous works have shown that plants with smaller and rounder seeds tend to have a higher survival rate in the digestive tracts of waterfowl than large or elongated seeds (Soons et al. 2008; Lovas-Kiss et al. 2020). This might partly explain the higher passage rate and lower retention time of the alien species, although even when these seed traits were included in our models, the influence of indigenous status (i.e. native or alien) remained significant. This suggests that there might be additional seed traits of key importance which contribute to the differences between alien and native species. Such a trait could be for instance seed hardness.

Effect of gut passage in germinability

Germinability reflects seed vigour and viability (Jiménez-Alfaro et al. 2016), that has a positive effect on species establishment, spread and impact (Colautti et al., 2006). Alien species commonly have a higher germinability than native species, and can germinate under broader environmental conditions (Gioria and Pyšek 2017). These patterns were observed for the control seeds in our experiment, for which germinability of alien species was higher (Table 2). However, effect disappeared when we controlled for differences in seed traits: smaller, more elongated control seeds had a higher germinability than larger, more round seeds, as recorded in previous studies (Vera 1997; Bu et al. 2016). These effects of indigenous status and seed shape were reversed for seeds that survived the various stressors during digestion, after which native species had a higher germinability. Perhaps the native seeds were better able to resist the mechanical scarification in the gizzard (Kleyheeg et al. 2018), leading to greater breaking of physiological seed dormancy (Lovas-Kiss et al. 2015).

Interestingly, previous studies found similar contradictory effects on germinability. Soons et al. (2008) found that smaller seeds had higher germinability, while Kleyheeg et al. (2018) found the opposite, although they did not control for seed shape. Gioria and Pyšek (2017) argued that germinability under one set of controlled conditions is not a reliable predictor of invasiveness, because germination patterns are strongly dependent on environmental conditions, so that alien species can only be expected to have a competitive advantage from high germination under certain conditions. For example, changing the salinity can radically change the germination response of wetland plants, and interact with the effects of gut passage by waterfowl (Espinar et al. 2004). In addition, the fact that the inclusion of seed traits had major effects in our models of germinability underlines the crucial role of seed traits, and suggests that the remaining partial effects of indigenous status may ultimately be explicable based on additional traits (e.g. thickness and water permeability of seed coat. Therefore, further studies with a larger set of species with a more diverse set of seed traits are needed to clarify these issues.

Seed dormancy plays a key role in the germination of the seeds, and can occur in several forms. Physiological and physical dormancy are the most common forms, of which physiological dormancy is the most common in aquatic non-salt tolerant (non-halophyte) plant species such as those that we used in our experiments. For example, Bidens frondosa needs approximately 270 days to break its dormancy after a cold stratification, so its low germinability (see Table 1) may be explained by this reason (Baskin \& Baskin, 2014). Only physical dormancy is considered to require gut passage by animals to be broken, leading to accelerated germination (Penfield 2017). However, our results bring the paradigm of dormancy strategies into question, since gut passage increased germinability in five of our twelve study species (Table 1). Theoretically, all the tested seeds had physiological dormancy, but they still seemed to be affected by the physical and chemical effects during their gut passage, similar to previous findings by (García-Álvarez et al., 2015). It is also important to note that 
despite detailed research into a range of factors (e.g. temperature, light, water, chemical concentrations) that stimulate entry into and exit from dormancy in such plants (Baskin \& Baskin, 2014), the role of gut passage has so far been ignored. Further research is needed to study the interactions between gut passage and other variables driving dormancy and germination in alien plants with physiological dormancy.

Relation time, time to germination and passage rate

The time a seed spends until germination has a crucial effect on its colonization potential and success. Species with fast germination can gain competitive advantages and can speed up the time needed for recruitment of the next generation (Jiménez-Alfaro et al. 2016). We found the control seeds of alien species showed significantly faster germination compared to native species, which is in line with previous studies (Pyšek \& Richardson, 2007; Gioria \& Pyšek, 2017). Germination time is often decreased by gut passage, but often also varies according to retention time (Brochet et al., 2010; Garcia-Alvarez et al. 2015), which in turn is related to seed traits that can differ between alien and native species. The seeds of native species stayed longer in the digestive tract, partly due to their bigger size, and this is likely to explain why they germinated faster after gut passage than alien seeds (Brochet et al. 2010). Overall, seed traits did not influence the effect of passage on germination time. We found that elongated seeds, both for controls and gut passage, persistently needed less time for germination. This result is consistent with previous studies showing that elongated seeds tend to germinate faster, compensating for other ecological effects in which seeds of such a shape are less likely to reach the seed bank and are exposed to higher predation pressure (Grime et al. 1981; Thompson 1987; Thompson et al. 1993; Bu et al. 2016). The effect of earlier germination on the fitness of wetland plants still needs more investigation, because it can have costs from increased herbivory, as well as benefits from more rapid growth (Figuerola et al., 2005; Figuerola \& Green, 2004).

Consequences for plant invasions

Dietary studies from Europe showed that ducks can disperse hundreds of plant species, including many aliens (Soons et al., 2016), and field data shows that this extends to many other waterbirds (see Introduction). Mallards (Kleyheeg et al. 2019) and other migratory waterbirds are very suitable vectors for longdistance dispersal (LDD). Although LDD events are rare, they are vital in facilitating population spread and determining local community structure (Nathan et al., 2008). We showed that waterfowl endozoochory can give alien plants an advantage for LDD by increasing their propagule pressure compared to native species, even though it can also delay germination. We also showed the important role of species traits in determining potential for endozoochory, notably through their influence on retention time and germination. Faster germination (together with a fast growth rate) can provide a competitive advantage, however, dispersal of a large number of small seeds with slower germination might also help species to avoid inappropriate environmental conditions, e.g. if seeds arrived in an early season. This combined with the faster growth rate and higher trait plasticity of alien species can ensure their overall competitive superiority (Ruprecht et al. 2014; Szabó et al. 2019). According to our results, gut passage did not affect the plasticity of germination time, however we need more information on its dependence on environmental variables. Such information supplemented with the knowledge on additional traits such as growth rate would allow us to predict the ability of alien species to expand their range.

\section{Declarations}

\section{Acknowledgements}

We are very grateful to Gábor Lovas-Kiss and Erika Buzás for their assistance during the experiment.

\section{Author Contribution}

The research was initiated and designed by BAL; the feeding trials were designed by ÁL-K and CvL; the experiment was performed by BAL, ÁL-K, MJN, FP-K and VL; sample preparation and germination experiment were done by RU and FP-K; data analyses were performed by OV; the manuscript was written by BAL, ÁLK, MJN, OV and AJG; all authors made essential contributions to revise the text.

\section{Funding}

The experiment was financed by the NKFIH OTKA FK-127939 grant. BAL, ÁL-K and OV were supported by the János Bolyai Research Scholarship of the Hungarian Academy of Sciences and by the New National Excellence Programme of the Hungarian Ministry of Innovation and Technology. AJG was supported by the Spanish Ministerio de Economía, Industria y Competitividad project CGL2016-76067-P (AEI/FEDER, EU) and MJN was supported by an FPI grant from the Spanish Ministerio de Ciencia, Innovación y Universidades (BES-2017-081599).

\section{Conflict of interest}

The authors declare that there is no conflict of interest.

\section{Data Availability}

Data used in the analyses are to be deposited in Figshare upon acceptance.

\section{Ethical permit}

The experiment had ethical approval from the scientific council of the Babeş-Bolyai University of Cluj Napoca (reference number: 14689/31.08.2018)

\section{Online Resources}

ESM1 Description of the twelve plant species used in the experiment. 
ESM2 Differences in time to germination of alien and native taxa of passed as well as control seeds.

\section{References}

1. Barnea A, Yom-Tov Y, Friedman J (1991) Does Ingestion by Birds Affect Seed Germination? Funct Ecol 5:394. https://doi.org/10.2307/2389811

2. Baskin C, Baskin J (2014) Seeds, 2nd edn. Elsevier

3. Bates D, Mächler M, Bolker B, Walker S (2015) Fitting Linear Mixed-Effects Models Using Ime4. J Stat Softw 67:1-48. https://doi.org/10.18637/jss.v067.i01

4. Bekker RM, Bakker JP, Grandin U et al (1998) Seed size, shape and vertical distribution in the soil: Indicators of seed longevity. Funct Ecol. https://doi.org/10.1046/j.1365-2435.1998.00252.x

5. Blackburn TM, Pyšek P, Bacher S et al (2011) A proposed unified framework for biological invasions. Trends Ecol Evol 26:333-339. https://doi.org/10.1016/j.tree.2011.03.023

6. Brochet AL, Guillemain M, Gauthier-Clerc M et al (2010) Endozoochory of Mediterranean aquatic plant seeds by teal after a period of desiccation: Determinants of seed survival and influence of retention time on germinability and viability. Aquat Bot 93:99-106. https://doi.org/10.1016/j.aquabot.2010.04.001

7. Bu H-Y, Wang X-J, Zhou X-H et al (2016) The ecological and evolutionary significance of seed shape and volume for the germination of 383 species on the eastern Qinghai-Tibet plateau. Folia Geobot 51:333-341. https://doi.org/10.1007/s12224-016-9271-y

8. Bullock JM, Mallada González L, Tamme R et al (2017) A synthesis of empirical plant dispersal kernels. J Ecol 105:6-19. https://doi.org/10.1111/13652745.12666

9. Colautti RI, Grigorovich IA, Maclsaac HJ (2006) Propagule Pressure: A Null Model for Biological Invasions. Biol Invasions 8:1023-1037. https://doi.org/10.1007/s10530-005-3735-y

10. Crawley M (2007) The R book. John Wiley \& Sons, Ltd., Chichester

11. Crawley MJ, Harvey PH, Purvis A (1996) Comparative ecology of the native and alien floras of the British Isles. Philos Trans R Soc London Ser B Biol Sci 351:1251-1259. https://doi.org/10.1098/rstb.1996.0108

12. Espinar JL, García LV, Figuerola J et al (2004) Helophyte germination in a Mediterranean salt marsh: Gut-passage by ducks changes seed response to salinity. J Veg Sci 15:315-322. https://doi.org/10.1111/j.1654-1103.2004.tb02267.x

13. Figuerola J, Green AJ (2004) Effects of seed ingestion and herbivory by waterfowl on seedling establishment: a field experiment with wigeongrass Ruppia maritima in Doñana, south-west Spain. Plant Ecol 173:33-38. https://doi.org/10.1023/B:VEGE.0000026323.56635.4e

14. Figuerola J, Santamaria L, Green AJ et al (2005) Endozoochorous dispersal of aquatic plants: does seed gut passage affect plant performance? Am J Bot 92:696-699. https://doi.org/10.3732/ajb.92.4.696

15. García-Álvarez A, van Leeuwen CHa, Luque CJ et al (2015) Internal transport of alien and native plants by geese and ducks: an experimental study. Freshw Biol 60:1316-1329. https://doi.org/10.1111/fwb.12567

16. Gioria M, Pyšek P (2017) Early bird catches the worm: germination as a critical step in plant invasion. Biol Invasions 19:1055-1080. https://doi.org/10.1007/s10530-016-1349-1

17. Green AJ, Baltzinger C, Lovas-Kiss Á (2021) Plant dispersal syndromes are unreliable, especially for predicting zoochory and long-distance dispersal. https://doi.org/10.1111/oik.08327. Oikos oik.08327

18. Green AJ, Elmberg J, Lovas-Kiss Á (2019) Beyond Scatter-Hoarding and Frugivory: European Corvids as Overlooked Vectors for a Broad Range of Plants. Front Ecol Evol 7:133. https://doi.org/10.3389/fevo.2019.00133

19. Grime JP, Mason G, Curtis AV et al (1981) A Comparative Study of Germination Characteristics in a Local Flora. J Ecol 69:1017. https://doi.org/10.2307/2259651

20. Gurd DB (2007) Predicting Resource Partitioning and Community Organization of Filter-Feeding Dabbling Ducks from Functional Morphology. Am Nat 169:334-343. https://doi.org/10.1086/510924

21. Guttal V, Bartumeus F, Hartvigsen G, Nevai AL (2011) Retention Time Variability as a Mechanism for Animal Mediated Long-Distance Dispersal. PLoS ONE 6:e28447. https://doi.org/10.1371/journal.pone.0028447

22. Hattermann D, Bernhardt-Römermann M, Otte A, Eckstein RL (2019) Geese are overlooked dispersal vectors for vascular plants in archipelago environments. J Veg Sci 30:533-541. https://doi.org/10.1111/jvs.12742

23. Higgins SI, Richardson DM (1999) Predicting Plant Migration Rates in a Changing World: The Role of Long-Distance Dispersal. Am Nat 153:464-475. https://doi.org/10.1086/303193

24. Jiménez-Alfaro B, Silveira FAO, Fidelis A et al (2016) Seed germination traits can contribute better to plant community ecology. J Veg Sci 27:637-645. https://doi.org/10.1111/jvs.12375

25. Kleyheeg E, Claessens M, Soons MB (2018) Interactions between seed traits and digestive processes determine the germinability of bird-dispersed seeds. PLoS ONE 13:e0195026. https://doi.org/10.1371/journal.pone.0195026

26. Kleyheeg E, Fiedler W, Safi K et al (2019) A Comprehensive Model for the Quantitative Estimation of Seed Dispersal by Migratory Mallards. Front Ecol Evol 7:40. https://doi.org/10.3389/fevo.2019.00040

27. Lockwood JL, Cassey P, Blackburn TM (2009) The more you introduce the more you get: the role of colonization pressure and propagule pressure in invasion ecology. Divers Distrib 15:904-910. https://doi.org/10.1111/j.1472-4642.2009.00594.x

Page 8/11 
28. Lovas-Kiss Á, Sánchez MI et al (2018) Crayfish invasion facilitates dispersal of plants and invertebrates by gulls. Freshw Biol 63:392-404. https://doi.org/10.1111/fwb.13080

29. Lovas-Kiss Á, Sonkoly J, Vincze 0 et al (2015) Strong potential for endozoochory by waterfowl in a rare, ephemeral wetland plant species, Astragalus contortuplicatus (Fabaceae). Acta Soc Bot Pol 84:321-326. https://doi.org/10.5586/asbp.2015.030

30. Lovas-Kiss Á, Sánchez MI, Wilkinson DM et al (2019) Shorebirds as important vectors for plant dispersal in Europe. Ecography (Cop) $42: 956-967$. https://doi.org/10.1111/ecog.04065

31. Lovas-Kiss Á, Vincze O, Kleyheeg E et al (2020) Seed mass, hardness, and phylogeny explain the potential for endozoochory by granivorous waterbirds. Ecol Evol 10:1413-1424. https://doi.org/10.1002/ece3.5997

32. Martín-Vélez V, Leeuwen CHA, Sánchez MI et al (2021) Spatial patterns of weed dispersal by wintering gulls within and beyond an agricultural landscape. J Ecol 109:1947-1958. https://doi.org/10.1111/1365-2745.13619

33. Nathan R, Schurr FM, Spiegel $O$ et al (2008) Mechanisms of long-distance seed dispersal. Trends Ecol Evol 23:638-647. https://doi.org/10.1016/j.tree.2008.08.003

34. Navarro-Ramos MJ, Green AJ, Lovas-Kiss A et al (2021) A predatory waterbird as a vector of plant seeds and aquatic invertebrates. Freshw Biol. https://doi.org/10.1111/fwb.13870

35. Penfield S (2017) Seed dormancy and germination. Curr Biol 27:R874-R878. https://doi.org/10.1016/j.cub.2017.05.050

36. Pollux BJA (2017) Consistent individual differences in seed disperser quality in a seed-eating fish. Oecologia 183:81-91. https://doi.org/10.1007/s00442016-3749-4

37. Pyšek P, Richardson DM (2008) Traits associated with invasiveness in alien plants: where do we stand? In: Nentwig W (ed) Biological invasions. Springer, Berlin, Heidelberg., pp 97-125

38. R Core Team (2021) R: A language and environment for statistical computing. https://www.r-project.org/

39. Richardson DM, Pysek P, Rejmanek M et al (2000) Naturalization and invasion of alien plants: concepts and definitions. Divers Distrib 6:93-107. https://doi.org/10.1046/j.1472-4642.2000.00083.x

40. Ruprecht E, Fenesi A, Nijs I (2014) Are plasticity in functional traits and constancy in performance traits linked with invasiveness? An experimental test comparing invasive and naturalized plant species. Biol Invasions 16:1359-1372. https://doi.org/10.1007/s10530-013-0574-0

41. Soons MB, Brochet AL, Kleyheeg E, Green AJ (2016) Seed dispersal by dabbling ducks: an overlooked dispersal pathway for a broad spectrum of plant species. J Ecol 104:443-455. https://doi.org/10.1111/1365-2745.12531

42. Soons MB, Van Der Vlugt C, Van Lith B et al (2008) Small seed size increases the potential for dispersal of wetland plants by ducks. J Ecol 96:619-627. https://doi.org/10.1111/j.1365-2745.2008.01372.x

43. Szabó S, Peeters ETHM, Várbíró G et al (2019) Phenotypic plasticity as a clue for invasion success of the submerged aquatic plant Elodea nuttallii. Plant Biol 21:54-63. https://doi.org/10.1111/plb.12918

44. Thompson K (1987) Seeds and seed banks. New Phytol 106:23-34. https://doi.org/10.1111/j.1469-8137.1987.tb04680.x

45. Thompson K, Band SR, Hodgson JG (1993) Seed Size and Shape Predict Persistence in Soil. Funct Ecol 7:236. https://doi.org/10.2307/2389893

46. Traveset A, Robertson A, Rodríguez-Pérez J (2007) A review on the role of endozoochory in seed germination. In: Dennis AJ, Schupp EW, Green RJ, Westcott DA (eds) Seed Dispersal: Theory and Its Application in a Changing World. CABI Publishing, Wallingford, UK, pp 78-103

47. van Kleunen M, Dawson W, Maurel N (2015) Characteristics of successful alien plants. Mol Ecol 24:1954-1968. https://doi.org/10.1111/mec.13013

48. van Leeuwen CHA (2018) Internal and External Dispersal of Plants by Animals: An Aquatic Perspective on Alien Interference. Front Plant Sci 9:153. https://doi.org/10.3389/fpls.2018.00153

49. van Leeuwen CHA, Lovas-Kiss Á, Ovegård M, Green AJ (2017) Great cormorants reveal overlooked secondary dispersal of plants and invertebrates by piscivorous waterbirds. Biol Lett 13:20170406. https://doi.org/10.1098/rsbl.2017.0406

50. van Leeuwen CHAA, van der Velde G, van Groenendael JM, Klaassen M (2012) Gut travellers: Internal dispersal of aquatic organisms by waterfowl. J Biogeogr 39:2031-2040. https://doi.org/10.1111/jbi.12004

51. Vera ML (1997) Effects of altitude and seed size on germination and seedling survival of heathland plants in north Spain. Plant Ecol 133:101-106. https://doi.org/10.1023/A:https://doi.org/10.1023/A:1009729201384

52. Viana DS, Santamaría L, Figuerola J (2016) Migratory Birds as Global Dispersal Vectors. Trends Ecol Evol 31:763-775. https://doi.org/10.1016/j.tree.2016.07.005

53. Zedler JB, Kercher S (2004) Causes and Consequences of Invasive Plants in Wetlands: Opportunities, Opportunists, and Outcomes. CRC Crit Rev Plant Sci 23:431-452. https://doi.org/10.1080/07352680490514673

\section{Figures}




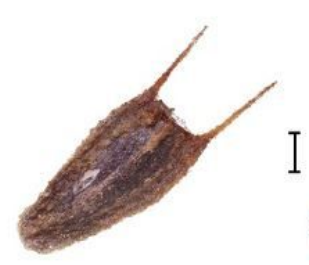

Bidens

frondosa

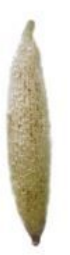

Najas

gracillima

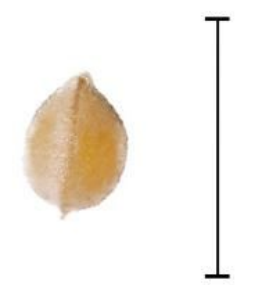

Cyperus
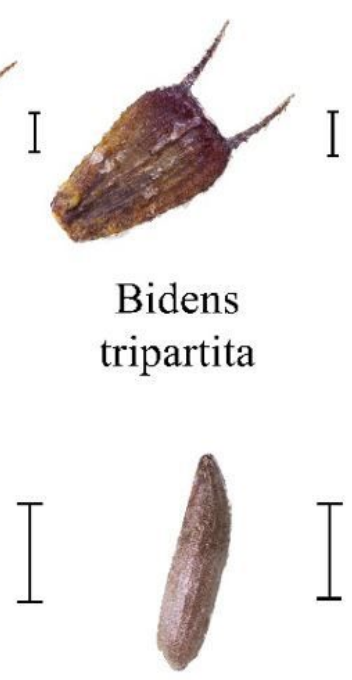

Bidens tripartita

Najas minor

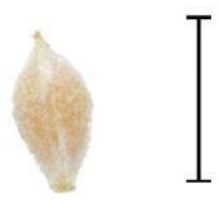

Cyperus

fuscus

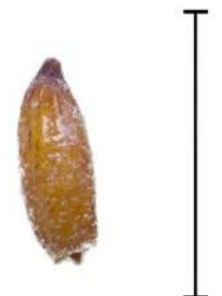

Typha

laxmannii

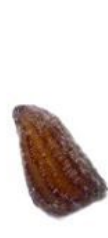

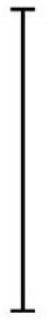

Juncus

tenuis

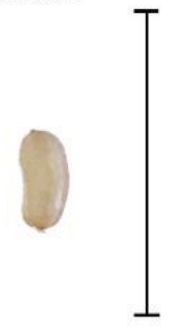

Lindernia dubia

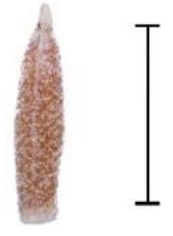

Typha

angustifolia

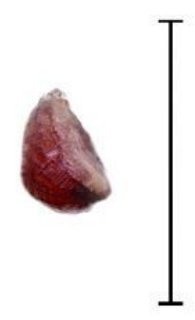

Juncus compressus

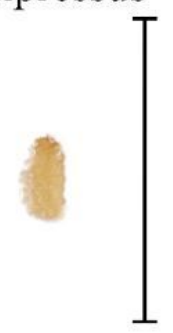

Lindernia

procumbens

Figure 1

Plant species and seeds involved in the feeding experiment. Bars represent $1 \mathrm{~mm}$. 


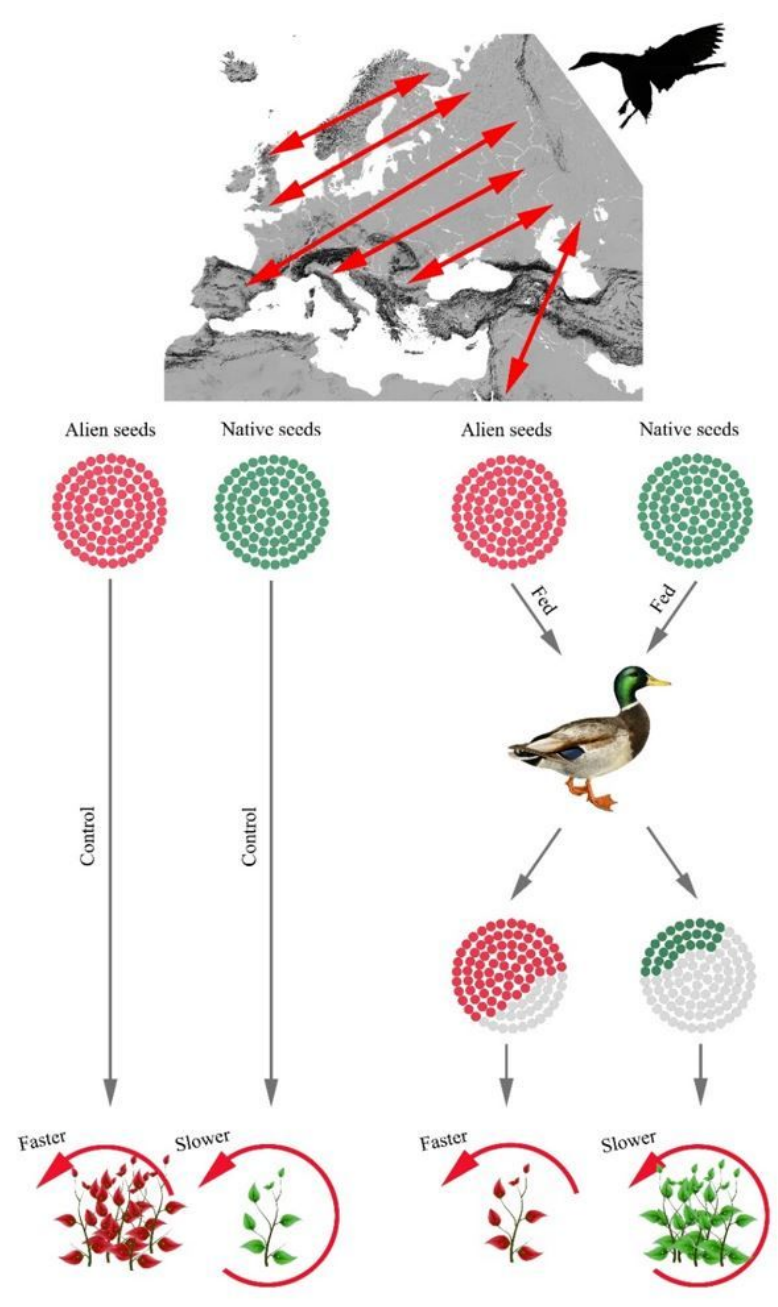

\section{Figure 2}

Schematic presentation of the experiment and results. The map depicting the movement of Mallard in Europe based on published information and ring recoveries (following the map of Delany et al., 2006). Dotted clusters (top) illustrate alien (red) and native (green) seeds used in the experiment in control (left two clusters) and seeds fed to mallards (right two clusters). The graph shows seed survival through gut passage (bottom dotted clusters), germinability (leafy plants) and germination time (red arrows). Grey dots mark seeds lost during digestion; the number of leafy plants represents the differences in germinability. Length of the red arrows indicates the time elapsed to germination compared to each other.

\section{Supplementary Files}

This is a list of supplementary files associated with this preprint. Click to download.

- LovasKissetalESM1.pdf 